544

Content list available at: https:/opendentistryjournal.com

RESEARCH ARTICLE

\title{
Position of the Mandibular Foramen in Different Facial Shapes Assessed by Cone-Beam Computed Tomography - A Cross-Sectional Retrospective Study
}

Silvan Correa ${ }^{1}$, Rogério H. Lopes Motta ${ }^{1}$, Milena B. Fellipe Silva ${ }^{1}$, Sidney R. Figueroba ${ }^{2, *}$, Francisco C. Groppo ${ }^{2}$ and Juliana C. Ramacciato ${ }^{1}$

${ }^{1}$ Faculdade São Leopoldo Mandic, Instituto de Pesquisas São Leopoldo Mandic. Dr. José Rocha Junqueira, 13 - Ponte Preta, Campinas - SP, Brazil ${ }^{2}$ Department of Physiological Sciences, Piracicaba Dental School, University of Campinas - UNICAMP. Av. Limeira, 901. Bairro Areiajo. Piracicaba, SP, Brazil

\begin{abstract}
:
Purpose:

The mandibular foramen, located on the internal surface of the mandibular ramus, is an important anatomical landmark for the success during the inferior alveolar nerve block. This cross-sectional retrospective study aimed to evaluate the location of the mandibular foramen through ConeBeam Computed Tomography (CBCT) in different facial shapes.

\section{Materials and Methods:}

The determination of the location of the mandibular foramen was performed using CBCT of mesocephalic, dolichocephalic and brachycephalic patients ( $\mathrm{n}=40$ each). The ramus width $(\mathrm{W})$, the distance from the mandibular foramen to the deepest point of the anterior border of the mandibular ramus (D), the distance from the mandibular foramen to the lowest point of the mandibular notch (V) and the distance from the inferior border of the mandible to the lowest point in of the mandibular border (R), as well as the ratios W/D and V/R, were measured. ANCOVA, two-way ANOVA and Chi-square tests were used to analyze the variation among the facial shapes.

Results:

The ramus width $(\mathrm{W})$ was greater $(p<0.0001)$ in the brachycephalic $(28.4 \pm 0.5 \mathrm{~mm})$ than in both mesocephalic $(26.8 \pm 0.36 \mathrm{~mm})$ and dolichocephalic $(25.5 \pm 0.39 \mathrm{~mm})$ patients. $\mathrm{D}(p=0.0433)$ and $\mathrm{R}(p=0.0072)$ were also greater in the brachycephalic $(17.7 \pm 0.36 \mathrm{~mm} ; 43.4 \pm 0.75 \mathrm{~mm}$, respectively $)$ than dolichocephalic $(16.5 \pm 0.3 \mathrm{~mm} ; 40.3 \pm 0.63 \mathrm{~mm}$, respectively), but both did not differ from mesocephalic (17.3 $\pm 0.36 \mathrm{~mm} ; 41.8 \pm 0.66 \mathrm{~mm}$ respectively) patients. The other measurements (V,W/D and $\mathrm{R} / \mathrm{V})$ did not significantly differ among facial shapes.

Conclusion:

The localization of the mandibular foramen was, in the horizontal direction, more posterior in the brachycephalic patients and, in the vertical direction, higher in the dolichocephalic patients, when compared to the other groups analyzed. Thus, the anatomic data found in this study may help dentists to increase the success of the inferior alveolar nerve block and prevent surgical complications.
\end{abstract}

Keywords: Mandibular foramen, CBCT, Facial shape, Anatomy, Brachycephalic patients, Dolichocephalic patients,

\begin{tabular}{|l|l|l|l|}
\hline Article History & Received: August 19, 2019 & Revised: November 07, 2019 & Accepted: December 10, 2019 \\
\hline
\end{tabular}

\section{INTRODUCTION}

The mandibular foramen is an irregular foramen located on the internal surface of the mandibular ramus, slightly above the center of the medial aspect of the mandibular ramus. The inferior alveolar nerve and vessels pass through the mandibular

\footnotetext{
* Address correspondence to this author at the Faculdade São Leopoldo Mandic, Instituto de Pesquisas São Leopoldo Mandic. Dr. José Rocha Junqueira, 13 Ponte Preta, Campinas - SP, Brazil; Tel: 5519 32113600;
}

E-mail: juliana.ramacciato@slmandic.edu.br foramen and traverse the mandibular canal to give origin to the mental and incisive nerves [1]. Inferior alveolar nerve block, one of the anesthetic techniques used in dental practice, has a reported failure rate of about $20 \%$ to $25 \%$, which is considered high [2].

The precise determination of the mandibular foramen is fundamental to achieving success in inferior alveolar nerve block and preventing common complications of orthognathic surgeries [3]. The location of the mandibular foramen changes 
with age, as it may be at the level of the occlusal plane in primary dentition and at a higher position in permanent dentition. Studies have demonstrated that there are racial differences in mandibular anatomy. Differences in measurements, morphology and biology are found between the three major racial phenotypes: Caucasian, mongoloid and negroid [4]. As the face grows, different mandibular growth and tooth eruption patterns result in variations in the location of the mandibular foramen. Several studies evaluated the location of the mandibular foramen in individuals of different ages and racial phenotypes, and some found that mandibular growth patterns may be affected by facial morphology [5].

The facial shape may affect the treatment plan because variations between individuals suggest changes in the structural position of certain anatomic landmarks. Facial shape, also called craniofacial shape, may be classified as: dolichocephalic-long and narrow face; brachycephalic-short and broad face; and mesocephalic-intermediate type [6]. In addition to facial shapes, malocclusions may affect the location of the mandibular foramen. Differences in mandibular dimensions are found in patients with skeletal class I (normal), class II and class III relationships [7].

According to [8] the mandibular foramen cannot be palpated clinically and its location is variable at the medial surface of the mandibular ramus. Nevertheless, determining its exact location is very important to the oral and maxillofacial surgeon for the relevant anesthetic and surgical ramus procedures.

Studies conducted to define the location of the mandibular foramen have used radiographic (panoramic and cephalometric) anatomic landmarks and computed tomography [9]. Recent advances in the imaging techniques of Cone Beam Computed Tomography (CBCT) have added safety to oral and maxillofacial surgeries. The most significant advantage of $\mathrm{CBCT}$ is that images have very small differences in magnification and distortion and thus provide accurate and reliable data [10].

The use of CBCT scans seems to be the best method to evaluate the location of the mandibular foramen, because CBCT images provide data for a detailed and accurate analysis, as well as for planning that is adequate to the treatment indicated, particularly in the case of surgical procedures that involve the mandibular ramus [3].

This study used CBCT to determine the location of the mandibular foramen according to possible clinical implications of anteroposterior and vertical anatomic variations in the mandibular ramus of different facial shapes.

\section{MATERIALS AND METHODS}

\subsection{Patients}

From a total of 613 CBCT scans of patients seen at the Radiology Center of the São Leopoldo Mandic School of Dentistry, in Campinas, Brazil, from January 2015 to December 2016, 120 met the inclusion criteria and were included in the sample. This study was approved by the Ethics Committee, Center for Dental Research and Faculty of
Dentistry São Leopoldo Mandic- Campinas, Brazil (protocol \#1.432.883). The CBCT used were taken from a database of patients who would undergo orthodontic treatment.

\subsection{Procedure}

The cephalometric analysis produced the Jarabak index, calculated as posterior facial height (S-Go) to anterior facial height (N-Me) times $100 \%$. These values were used to classify patients into three groups of 40 each: mesocephalic, dolichocephalic and brachycephalic. Patients were 18 to 25 years old, with no significant differences in sex or occlusion relationship. Skeletal malocclusion was determined using A-Po (Ricketts) facial convexity.

\subsection{Radiographic Examination}

The images were acquired using an i-Cat scanner (KAVO, Imaging Sciences International Hatfield, PA), ad medium 5x5 angio sharpen filter and the scanner's Xoram software according to the following parameters: $120 \mathrm{KvP}, 36 \mathrm{~mA}$ and exposure time of 20 seconds. CBCT images were acquired as digital imaging and communication in medicine (DICOM) format and had a safety code or number, which blocked changes and ensured their legal validity. The positioning of CBCT images was standardized before the sections were selected for measurements. The radiologist responsible for the imaging studies used the i-CAT scanner's Xoram 3.1.62 software. The same professional performed standardization and measurements of CBCT scans that were previously selected, at different time points.

\subsection{Cone Beam Computed Tomography (CBCT) Analysis}

The Mandibular Foramen (MF) was located together with the opening of the mandibular canal. The deepest point of the anterior border of the mandibular ramus was called ' $a$ ', and the lowest point of the mandibular notch was called 's'. The comparison of anterior and posterior positions of the mandibular foramen was defined by the measurement of the distance $(\mathrm{D}$, in $\mathrm{mm})$ between ' $\mathrm{a}$ ' and MF and the shortest distance $(\mathrm{W}$, in $\mathrm{mm}$ ) between ' $\mathrm{a}$ ' and the posterior border of the mandibular ramus. The vertical position of the mandibular foramen was assessed using the distance $(\mathrm{V}$, in $\mathrm{mm})$ between ' $\mathrm{s}$ ' and MF and the shortest distance ( $\mathrm{R}$, in $\mathrm{mm}$ ) between ' $\mathrm{s}$ ' and the inferior border of the mandible (Table $\mathbf{1}$ ).

Table 1. Measures and landmarks.

\begin{tabular}{|c|c|}
\hline Abbreviation & Measurements \\
\hline W & Mandibular ramus width (anteroposterior) \\
\hline $\mathrm{D}$ & $\begin{array}{l}\text { Distance from mandibular anterior border to } \\
\text { mandibular foramen }\end{array}$ \\
\hline $\mathrm{R}$ & Height of mandibular ramus \\
\hline V & $\begin{array}{l}\text { Distance from mandibular notch to mandibular } \\
\text { foramen }\end{array}$ \\
\hline $\mathrm{W} / \mathrm{D}$ & Ratio determined by mandibular width \\
\hline $\mathrm{R} / \mathrm{V}$ & Ratio determined by mandibular height \\
\hline $\mathrm{a}$ & Deepest point of anterior mandibular border \\
\hline $\mathrm{s}$ & Lowest point of mandibular notch \\
\hline
\end{tabular}

$\mathrm{CBCT}$ images were reconstructed in a panoramic view. All 
distances were measured on both sides of the mandibular ramus. The measurements were determined by tracing the selected image structures, as shown in Fig. (1). Firstly, measurements were made in the three groups of patients (mesocephalic, brachycephalic and dolichocephalic). After that, comparisons of individuals of the same sex were made between the three groups. After men and women in the same group were compared, comparisons between patients according to skeletal class (I, II and III) were made.

\subsection{Statistical Analysis}

Initially, all variables were tested using the Levene tests to check homogeneity of variance and the Shapiro-Wilk test to test normal distribution. All variables with or without reciprocal transformation had a normal distribution and homogeneous variance. All numeric variables for the three facial forms were compared using Analysis of Covariance (ANCOVA) followed by the Tukey test, considering the patient's age as the covariable. A Chi-square test was used to compare facial forms. Two-way ANOVA, followed by the Tukey test, was used to detect differences between facial forms, considering sex and malocclusion or skeletal class, and the variables $\mathrm{D}, \mathrm{W}, \mathrm{R}$ and $\mathrm{V}$, as well as the $\mathrm{W} / \mathrm{D}$ and $\mathrm{V} / \mathrm{R}$ ratios. The possible associations between $\mathrm{W}, \mathrm{D}, \mathrm{R}, \mathrm{V}, \mathrm{W} / \mathrm{D}$ and $\mathrm{R} / \mathrm{V}$ were analyzed using the Pearson correlation test considering all the facial forms, together and separately. The level of significance was set at $5 \%(p<0.05)$ for all the tests. The statistic programs used in the analysis were GraphPad Prism 7.0, BioEstat 5.0 and Systat 13.0.

\section{RESULTS}

Table 2 shows the profile of individuals in each group and reveals that there were no statistically significant differences between groups in the distribution of participants according to sex, although there was a clear predominance of women $(p<0.0001)$ in the sample. There were no statistically significant differences among groups in the distribution of class I, II and III relationships, but there was clearly a smaller number of participants with class III malocclusion $(p<0.0001)$ than with class I and II in the three groups.

There was also a greater proportion of skeletal class I (according to A-Po) relationship among brachycephalic individuals than in the other groups; in the dolichocephalic and mesocephalic groups, there were more participants with class II malocclusion. The mandibular plane angle of dolichocephalic participants was higher (open angle), and there was a greater proportion of angles close to normality in the brachycephalic and mesocephalic groups. Due to variability, maxillary and mandibular protrusion or retrusion, as well as individual bite patterns, were not evaluated.

Table 3 shows the cephalometric values for each study group. There was no effect of age on any of the cephalometric results. Dolichocephalic individuals had greater facial convexity, inferior facial height (Ricketts) and FMA (Tweed) than mesocephalic and brachycephalic participants; in mesocephalic individuals, in turn, these values were greater than those found for brachycephalic participants. In the brachycephalic group, facial axis angle, facial depth and mandibular arch (Ricketts) were significantly greater than in both dolichocephalic and mesocephalic groups, but the mesocephalic group had greater measures than those in the dolichocephalic group. Therefore, the cephalometric landmarks studied here may be used to characterize facial forms and confirm the facial patterns, initially determined in our sample using the Jarabak analysis.

Table 2. Sample characteristics: sex, age, skeletal and malocclusion class.

\begin{tabular}{|c|c|c|c|c|c|c|}
\hline \multicolumn{2}{|c|}{ Variables } & \multirow{2}{*}{$\begin{array}{c}\begin{array}{c}\text { Brachy } \\
\text { Cephalic }\end{array} \\
21.2 \pm 11.7\end{array}$} & \multirow{2}{*}{$\begin{array}{c}\begin{array}{c}\text { Dolicho } \\
\text { Cephalic }\end{array} \\
20.4 \pm 11.3\end{array}$} & \multirow{2}{*}{$\begin{array}{c}\begin{array}{c}\text { Meso } \\
\text { Cephalic }\end{array} \\
21.7 \pm 14.0\end{array}$} & \multirow{2}{*}{$\begin{array}{c}\text { Total } \\
21.1 \pm 12.3\end{array}$} & \multirow{2}{*}{$\frac{p}{0.89^{*}}$} \\
\hline Age (years) & Mean \pm SD & & & & & \\
\hline \multirow{2}{*}{ Sex } & Women & $34(85.0 \%)$ & $29(72.5 \%)$ & $28(70.0 \%)$ & $91(75.8 \%)$ & \multirow{2}{*}{0.24} \\
\hline & Men & $6(15.0 \%)$ & $11(27.5 \%)$ & $12(30.0 \%)$ & $29(24.2 \%)$ & \\
\hline \multirow{3}{*}{ Molar class } & I & $20(50.0 \%)$ & $23(57.5 \%)$ & $17(42.5 \%)$ & $60(50.0 \%)$ & \multirow{3}{*}{0.28} \\
\hline & II & $16(40.0 \%)$ & $17(42.5 \%)$ & $20(50.0 \%)$ & $53(44.2 \%)$ & \\
\hline & III & $4(10.0 \%)$ & - & $3(7.5 \%)$ & $7(5.8 \%)$ & \\
\hline \multirow{3}{*}{$\begin{array}{l}\text { Skeletal } \\
\text { class A-Po }\end{array}$} & I & $24(60.0 \%)$ & $5(12.5 \%)$ & $13(32.5 \%)$ & $42(35.0 \%)$ & \multirow{3}{*}{$<0.0001$} \\
\hline & II & $4(10.0 \%)$ & $35(87.5 \%)$ & $25(62.5 \%)$ & $64(53.3 \%)$ & \\
\hline & III & $12(30.0 \%)$ & - & $2(5.0 \%)$ & $14(11.7 \%)$ & \\
\hline \multirow{3}{*}{$\begin{array}{c}\text { Mandibular } \\
\text { plan angle }\end{array}$} & High & - & $26(65.0 \%)$ & $4(10.0 \%)$ & $30(25.0 \%)$ & \multirow{3}{*}{$<0.0001$} \\
\hline & Low & $12(30.0 \%)$ & - & - & $12(10.0 \%)$ & \\
\hline & Normal & $28(70.0 \%)$ & $14(35.0 \%)$ & $36(90.0 \%)$ & $78(65.0 \%)$ & \\
\hline
\end{tabular}

Table 3. Mean ( \pm SD) cephalometric values.

\begin{tabular}{|c|c|c|c|c|}
\hline Variables & $\begin{array}{c}\text { Brachy } \\
\text { Cephalic }\end{array}$ & $\begin{array}{c}\text { Dolicho } \\
\text { Cephalic }\end{array}$ & $\begin{array}{c}\text { Meso } \\
\text { Cephalic }\end{array}$ & $\boldsymbol{p}$ \\
\hline Facial convexity (Ricketts) & $0.9( \pm 0.41)^{\mathbf{a}}$ & $4.1( \pm 0.47)^{\mathbf{b}}$ & $2.7( \pm 0.41)^{\mathbf{c}}$ & $<0.0001$ \\
\hline Lower facial height (Ricketts) & $39.6( \pm 0.63)^{\mathbf{a}}$ & $49.4( \pm 0.52)^{\mathbf{b}}$ & $44.8( \pm 0.47)^{\mathbf{c}}$ & $<0.0001$ \\
\hline
\end{tabular}


(Table 3) contd.....

(Table 3) contd.....
\begin{tabular}{|c|l|l|l|l|}
\hline Facial angle or facial depth (Ricketts) & $92.1( \pm 0.43)^{\mathbf{a}}$ & $85.7( \pm 0.35)^{\mathbf{b}}$ & $89.0( \pm 0.39)^{\mathbf{c}}$ & $<0.0001$ \\
\hline Facial axis angle (Ricketts) & $94.2( \pm 0.56)^{\mathbf{a}}$ & $85.0( \pm 0.52)^{\mathbf{b}}$ & $89.4( \pm 0.49)^{\mathbf{c}}$ & $<0.0001$ \\
\hline Mandibular arch angle (Ricketts) & $38.5( \pm 0.77)^{\mathbf{a}}$ & $27.5( \pm 0.56)^{\mathbf{b}}$ & $31.7( \pm 0.64)^{\mathbf{c}}$ & $<0.0001$ \\
\hline FMA degrees (Tweed) & $19.7( \pm 0.59)^{\mathbf{a}}$ & $32.1( \pm 0.59)^{\mathbf{b}}$ & $24.8( \pm 0.29)^{\mathbf{c}}$ & $<0.0001$ \\
\hline
\end{tabular}

The ramus width $(\mathrm{W})$, the distance from the mandibular foramen to the deepest point of the anterior border of the mandibular ramus (D), the distance from the mandibular foramen to the lowest point of the mandibular notch (V) and the distance from the inferior border of the mandible to the lowest point in of the mandibular border (R), as well as W/D and $\mathrm{V} / \mathrm{R}$, are shown in (Table 4). W was highest in the brachycephalic group, followed by the mesocephalic and then the dolichocephalic groups, and this difference was statistically significant. Both $\mathrm{D}$ and $\mathrm{R}$ were also greater in the brachycephalic than in the dolichocephalic group, but these measures were not different between these two groups and the mesocephalic group. The values of $\mathrm{V}$, as well as $\mathrm{W} / \mathrm{D}$ and $\mathrm{R} / \mathrm{V}$, were not significantly different between groups. The values of $\mathrm{W}$ were significantly different between patients with skeletal class I, II and III relationships in the brachycephalic group when compared with those in the mesocephalic and dolichocephalic groups, as shown in (Table 5).

Table 4. Values of $W, D, W / D, R, V$ and $R / V$ according to sex.

\begin{tabular}{|c|c|c|c|c|c|}
\hline \multicolumn{2}{|c|}{ Variables } & $\begin{array}{c}\text { Brachy } \\
\text { Cephalic }\end{array}$ & $\begin{array}{l}\text { Dolicho } \\
\text { Cephalic }\end{array}$ & $\begin{array}{c}\text { Meso } \\
\text { Cephalic }\end{array}$ & $p$ \\
\hline \multirow{6}{*}{$\begin{array}{l}\text { Both } \\
\text { sexes }\end{array}$} & W & $28.4( \pm 0.5)^{\mathrm{a}}$ & $25.5( \pm 0.39)^{\mathbf{b}}$ & $26.8( \pm 0.36)^{\mathrm{c}}$ & $<0.0001$ \\
\hline & D & $17.7( \pm 0.36)^{\mathrm{a}}$ & $16.5( \pm 0.3)^{\mathrm{b}}$ & $17.3( \pm 0.36)^{\text {ab }}$ & 0.0433 \\
\hline & $\mathbf{R}$ & $43.4( \pm 0.75)^{\mathrm{a}}$ & $40.3( \pm 0.63)^{\mathbf{b}}$ & $41.8( \pm 0.66)^{\text {ab }}$ & 0.0072 \\
\hline & $\mathbf{V}$ & $18.0( \pm 0.53)^{a}$ & $16.9( \pm 0.44)^{a}$ & $17.5( \pm 0.53)^{\mathrm{a}}$ & 0.25 \\
\hline & W/D & $1.6( \pm 0.02)^{\mathrm{a}}$ & $1.6( \pm 0.02)^{\mathrm{a}}$ & $1.6( \pm 0.02)^{\mathrm{a}}$ & 0.14 \\
\hline & $R / V$ & $2.5( \pm 0.05)^{\mathrm{a}}$ & $2.4( \pm 0.05)^{\mathrm{a}}$ & $2.5( \pm 0.06)^{\mathrm{a}}$ & 0.92 \\
\hline \multirow{2}{*}{ D } & Women & $17.5( \pm 0.37)$ & $16.2( \pm 0.38)$ & $16.9( \pm 0.33)$ & \multirow{2}{*}{0.06} \\
\hline & Men & $19.0( \pm 1.07)$ & $17.5( \pm 0.36)$ & $18.4( \pm 0.88)$ & \\
\hline \multirow{2}{*}{$\mathbf{R}$} & Women & $43.0( \pm 0.75)$ & $40.2( \pm 0.81)$ & $42.3( \pm 0.79)$ & \multirow{2}{*}{0.0052} \\
\hline & Men & $45.8( \pm 2.65)$ & $40.6( \pm 0.89)$ & $40.7( \pm 1.19)$ & \\
\hline \multirow{2}{*}{ V } & Women & $17.8( \pm 0.56)$ & $17.1( \pm 0.56)$ & $17.7( \pm 0.63)$ & \multirow{2}{*}{0.10} \\
\hline & Men & $19.3( \pm 1.46)$ & $16.2( \pm 0.57)$ & $16.9( \pm 0.99)$ & \\
\hline \multirow{2}{*}{$\mathbf{W}$} & Women & $28.2( \pm 0.53)$ & $25.0( \pm 0.47)$ & $26.7( \pm 0.44)$ & \multirow{2}{*}{0.0007} \\
\hline & Men & $29.4( \pm 1.44)$ & $26.8( \pm 0.62)$ & $26.9( \pm 0.64)$ & \\
\hline \multirow{2}{*}{$\mathrm{R} / \mathrm{V}$} & Women & $2.5( \pm 0.06)$ & $2.4( \pm 0.06)$ & $2.5( \pm 0.07)$ & \multirow{2}{*}{0.97} \\
\hline & Men & $2.4( \pm 0.15)$ & $2.5( \pm 0.05)$ & $2.5( \pm 0.09)$ & \\
\hline \multirow{2}{*}{ W/D } & Women & $1.6( \pm 0.02)$ & $1.6( \pm 0.03)$ & $1.6( \pm 0.03)$ & \multirow{2}{*}{0.41} \\
\hline & Men & $1.6( \pm 0.04)$ & $1.5( \pm 0.03)$ & $1.5( \pm 0.05)$ & \\
\hline
\end{tabular}

Table 5. Values of $\mathrm{W}, \mathrm{D}, \mathrm{W} / \mathrm{D}, \mathrm{R}, \mathrm{V}$ and $\mathrm{R} / \mathrm{V}$ according to skeletal class.

\begin{tabular}{|c|c|c|c|c|c|}
\hline & $\begin{array}{c}\text { Skeletal } \\
\text { Class }\end{array}$ & $\begin{array}{c}\text { Brachy } \\
\text { Cephalic }\end{array}$ & $\begin{array}{c}\text { Dolicho } \\
\text { Cephalic }\end{array}$ & $\begin{array}{c}\text { Meso } \\
\text { Cephalic }\end{array}$ & $p$ \\
\hline \multirow{3}{*}{$\mathbf{W}$} & I & $28.6( \pm 0.76)^{a}$ & $25.9( \pm 0.41)^{\mathbf{b}}$ & $26.4( \pm 0.62)^{\mathrm{c}}$ & \multirow{3}{*}{$<0.0001$} \\
\hline & II & $28.2( \pm 0.74)^{a}$ & $25.1( \pm 0.75)^{b}$ & $27.2( \pm 0.42)^{\mathrm{c}}$ & \\
\hline & III & $28.4( \pm 1.71)^{\mathrm{a}}$ & - & $26.4( \pm 1.89)^{\mathrm{c}}$ & \\
\hline \multirow{3}{*}{$R / \mathbf{V}$} & I & $2.4( \pm 0.05)$ & $2.5( \pm 0.06)$ & $2.4( \pm 0.11)$ & \multirow{3}{*}{0.90} \\
\hline & II & $2.5( \pm 0.1)$ & $2.4( \pm 0.08)$ & $2.5( \pm 0.06)$ & \\
\hline & III & $2.6( \pm 0.25)$ & - & $2.4( \pm 0.09)$ & \\
\hline \multirow{3}{*}{ W/D } & I & $1.6( \pm 0.02)$ & $1.5( \pm 0.03)$ & $1.6( \pm 0.03)$ & \multirow{3}{*}{0.45} \\
\hline & II & $1.5( \pm 0.03)$ & $1.6( \pm 0.03)$ & $1.5( \pm 0.04)$ & \\
\hline & III & $1.7( \pm 0.06)$ & - & $1.6( \pm 0.12)$ & \\
\hline
\end{tabular}




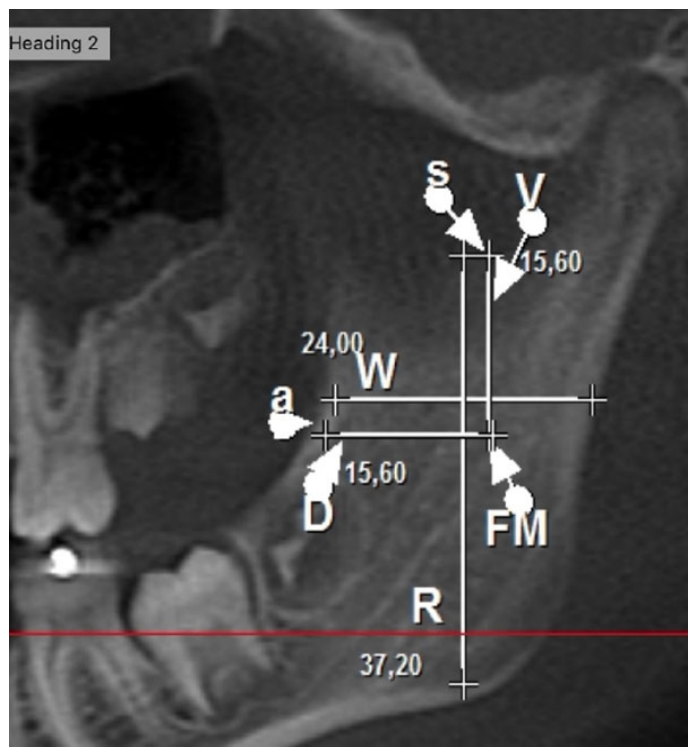

Fig. (1). Pattern of tomographic measurements used in the study (Wmandibular ramus width; D- distance from mandibular anterior border to mandibular foramen; R- Height of mandibular ramus; V- Distance from mandibular notch to mandibular foramen; FM- mandibular foramen; a- Deepest point of anterior mandibular border; s- Lowest point of mandibular notch.

Table 6 shows the values of $\mathrm{W}, \mathrm{D}, \mathrm{R}$ and $\mathrm{V}$, as well as $\mathrm{W} / \mathrm{D}$ and $\mathrm{R} / \mathrm{V}$, considering all facial forms together or separately. The values of W/D were not correlated with those of $\mathrm{R} / \mathrm{V}$ in any of the facial forms or in the whole group of patients. This indicates that there is no important association between height and width of the mandibular ramus. This finding was the same for all the measures assessed, regardless of facial form.

\section{DISCUSSION}

Several studies have investigated the location of the MF and its distance to neighboring structures. The determination of MF location in dentistry is essential for the success of the mental nerve block, as this technique requires the exact positioning of the needle close to the MF [11]. It is important for the prevention of surgical complications that may involve anatomic variations such as multiple mental foramina $[12,13]$. In this context, the size, length and width of the mandibular ramus have individual variations, and unexpected changes in a treatment plan may be necessary if the patient's facial form is not taken into consideration during diagnosis. Moreover, both clinicians and patients want a predictable and successful inferior alveolar nerve block (IANB). If the clinician can accurately recognize the anatomical location of the mandibular foramen and inject the anesthetic into the pterygomandibular space, the IANB success rate would be increased [14]. Dos Santos Oliveira et al. [15] observed that facial type was significantly associated with the path and morphological variations of the mandibular canal, independently of the side of the face studied, age, and sex.

There were no significant differences in sex, although our study sample was composed of mostly women with skeletal class II malocclusion, according to the A-Po values using Ricketts analysis. This result is similar to samples reported in other studies about the position of the mandibular foramen $[3,7]$. Of the measures associated with the position of the mandibular foramen in our study and correlated with facial form, only the width of the mandibular ramus (W) was greater in brachycephalic individuals, regardless of skeletal relationship (class I, II, or III) or sex, than in dolichocephalic and mesocephalic individuals. Similar W values were reported by Park and Lee [3], who also did not find any differences between sex and malocclusion. In a study about the anatomic location of the mandibular foramen using CBCT [16], differences between sexes in mandibular ramus width in individuals with different relationships (class I, II or III) were not found. A study with children did not find any differences in the width of the mandibular ramus between boys and girls [17]. Although our sample was composed of mostly women, sex did not affect our results.

Park and Lee [3] found a difference in the distance of the mandibular lower border from 's' (R) in the group of class II individuals, in which $\mathrm{R}$ was smaller than in the groups of the other skeletal classes. In our study, most participants with class II malocclusion had a dolichocephalic facial form, and a smaller number of individuals had a brachycephalic form. When considering the predominance of dolichocephalic form and class II relationship, our results were similar to those reported by two authors. The distance between MF and the occlusal plan may be affected by age and the patient's vertical growth pattern. This distance seems to be greater in individuals with a short face than in those with a long face. This distance may be shorter in individuals with a dolichocephalic facial form during growth because of several factors. The intermaxillary angle in individuals with a long face is greater than in individuals with a short (brachycephalic) or normal (mesocephalic) face [7]. The distance from the mandibular notch to the FM in our study was shorter in the dolichocephalic group. Park and Lee [3] found lower values in the group of individuals with class II relationships.

Table 6. Correlation (Pearson test) between $\mathrm{W}, \mathrm{D}, \mathrm{R}, \mathrm{V}, \mathrm{W} / \mathrm{D}$ and $\mathrm{R} / \mathrm{V}$ in all facial shapes.

\begin{tabular}{|c|c|c|c|c|c|c|}
\hline & & \multicolumn{5}{|c|}{ Correlation (rP) between Measures } \\
\hline & - & $\mathbf{W}$ & $\mathbf{D}$ & $\mathbf{R}$ & $\mathbf{V}$ & W/D \\
\hline \multirow{4}{*}{ All facial forms } & $\mathbf{D}$ & $0.69, p<0.0001$ & - & - & - & - \\
\cline { 2 - 8 } & $\mathbf{R}$ & $0.31, p=0.0005$ & $0.1, p=0.29$ & - & - & - \\
\cline { 2 - 7 } & $\mathbf{V}$ & $-0.01, p=0.94$ & $-0.05, p=0.61$ & $0.71, p<0.0001$ & - & - \\
\cline { 2 - 7 } & $\mathbf{W} / \mathbf{D}$ & $0.21, p=0.0185$ & $-0.55, p<0.0001$ & $0.23, p=0.0118$ & $0.05, p=0.56$ & - \\
\cline { 2 - 7 } & $\mathbf{R} / \mathbf{V}$ & $0.28, p=0.0018$ & $0.14, p=0.12$ & $-0.18, p=0.06$ & $-0.8, p<0.0001$ & $0.14, p=0.12$ \\
\hline
\end{tabular}




\begin{tabular}{|c|c|c|c|c|c|c|}
\hline \multirow{5}{*}{ Brachycephalic } & D & $0.78, \mathrm{p}<0.0001$ & - & - & - & - \\
\hline & $\mathbf{R}$ & $0.14, p=0.40$ & $0.04, p=0.81$ & - & - & - \\
\hline & $\mathbf{V}$ & $-0.17, p=0.31$ & $-0.23, p=0.16$ & $0.78, p<0.0001$ & - & - \\
\hline & $\mathbf{W} / \mathbf{D}$ & $0.17, p=0.30$ & $-0.49, p=0.0015$ & $0.09, p=0.58$ & $0.08, p=0.62$ & - \\
\hline & $\mathrm{R} / \mathrm{V}$ & $0.36, p=0.0244$ & $0.36, p=0.0216$ & $-0.33, p=0.0356$ & $-0.84, p<0.0001$ & $-0.03, p=0.85$ \\
\hline \multirow{5}{*}{ Dolichocephalic } & D & $0.62, p<0.0001$ & - & - & - & - \\
\hline & $\mathbf{R}$ & $0.27, p=0.09$ & $-0.07, p=0.68$ & - & - & - \\
\hline & $\mathbf{V}$ & $0.01, p=0.96$ & $-0.12, p=0.46$ & $0.66, p<0.0001$ & - & - \\
\hline & W/D & $0.24, \mathrm{p} p=0.14$ & $-0.61, p<0.0001$ & $0.34, p=0.0304$ & $0.15, p=0.36$ & - \\
\hline & $\mathrm{R} / \mathrm{V}$ & $0.23, p=0.15$ & $0.08, p=0.61$ & $-0.04, p=0.79$ & $-0.77, p<0.0001$ & $0.13, p=0.42$ \\
\hline \multirow{5}{*}{ Mesocephalic } & $\mathbf{D}$ & $0.62, p<0.0001$ & - & - & \begin{tabular}{|l|}
- \\
\end{tabular} & - \\
\hline & $\mathbf{R}$ & $0.31, p=0.06$ & $0.12, p=0.48$ & - & - & - \\
\hline & $\mathbf{V}$ & $-0.03, p=0.84$ & $0.08, p=0.63$ & $0.66, p<0.0001$ & - & - \\
\hline & $\mathbf{W} / \mathbf{D}$ & $0.09, p=0.58$ & $-0.71, p<0.0001$ & $0.16, p=0.31$ & $-0.11, p=0.5$ & - \\
\hline & $\mathbf{R} / \mathbf{V}$ & $0.29, p=0.07$ & $-0.02, p=0.89$ & $-0.17, p=0.29$ & $-0.84, p<0.0001$ & $0.28, p=0.08$ \\
\hline
\end{tabular}

After the analysis of results, this study showed that the MF is more posteriorly located horizontally in individuals with a brachycephalic facial form than in those with a dolichocephalic form according to the values of $\mathrm{D}$. The values of $\mathrm{V}$ showed that the MF is located at a lower position vertically in the brachycephalic group of individuals and at a higher position in the dolichocephalic group. Thus, the anatomic data found in this study may help dentists to increase the success of the inferior alveolar nerve block and prevent surgical complications.

\section{CONCLUSION}

Sex did not affect the results, and there were no significant associations between height and width of the mandibular ramus, regardless of facial form. The localization of the mandibular foramen was, in the horizontal direction, more posterior in the brachycephalic patients and, in the vertical direction, higher in the dolichocephalic patients when compared to the other groups analyzed.

\section{ABBREVIATIONS}

CBCT: Cone-Beam Computed Tomography

\section{AUTHORS' CONTRIBUTIONS}

$\mathrm{SC}$ and MLFS contributed to the study design, and data acquisition, analysis and interpretation. SRF and FCG statistically analyzed the data. JCR and RHLM conceived of the study, and contributed to its design and coordination. SRF and FCG wrote the manuscript draft, and critically revised it for important intellectual content. All authors read and approved the final manuscript.

\section{ETHICS APPROVAL AND CONSENT TO PARTICIPATE}

This study was approved by the Ethics Committee, Center for Dental Research and Faculty of Dentistry São Leopoldo Mandic- Campinas, Brazil (protocol \#1.432.883).

\section{HUMAN AND ANIMAL RIGHTS}

No animals were used in this research. All research procedures on humans were followed in accordance with the ethical standards of the committee responsible for human experimentation (institutional and national), and with the Helsinki Declaration of 1975, as revised in 2013. (http://ethics.iit.edu/ecodes/node/3931).

\section{CONSENT FOR PUBLICATION}

The patient signed a consent form to be involved in this study.

\section{AVAILABILITY OF DATA AND MATERIAL}

The data that support the findings of this study are available from the corresponding author JCR upon reasonable request.

\section{FUNDING}

None.

\section{CONFLICT OF INTEREST}

The authors declare no conflict of interest, financial or otherwise.

\section{ACKNOWLEDGEMENTS}

Declared none.

\section{REFERENCES}

[1] Yu SK, Kim S, Kang SG, et al. Morphological assessment of the anterior loop of the mandibular canal in Koreans. Anat Cell Biol 2015; 48(1): 75-80

[http://dx.doi.org/10.5115/acb.2015.48.1.75] [PMID: 25806125]

[2] Shalini R, RaviVarman C, Manoranjitham R, Veeramuthu M. Morphometric study on mandibular foramen and incidence of accessory mandibular foramen in mandibles of south Indian population and its clinical implications in inferior alveolar nerve block. Anat Cell Biol 2016; 49(4): 241-8.

[http://dx.doi.org/10.5115/acb.2016.49.4.241] [PMID: 28127498]

[3] Park HS, Lee JH. A comparative study on the location of the mandibular foramen in CBCT of normal occlusion and skeletal class II and III malocclusion. Maxillofac Plast Reconstr Surg 2015; 37(1): 25. [http://dx.doi.org/10.1186/s40902-015-0024-2] [PMID: 26301208]

[4] Sandhya K, Singh B, Lugun N, Prasad R. Localization of mandibular foramen relative to landmarks in East Indian mandibles. Indian J Dent Res 2015; 26(6): 571-5.

[http://dx.doi.org/10.4103/0970-9290.176917] [PMID: 26888233]

[5] Paryab M, Ahmadyar M. Locating mandibular foramen in children with mandibular retrognathism in mixed dentition. J Dent Res Dent 
Clin Dent Prospect 2015; 9(2): 66-71

[http://dx.doi.org/10.15171/joddd.2015.014] [PMID: 26236430]

[6] Benedicto EN, Kairalla SA, Oliveira GMS, Junior LRM, Rosário HD Paranhos LR. Determination of vertical characteristics with different cephalometric measurements. Eur J Dent 2016; 10(1): 116-20. [http://dx.doi.org/10.4103/1305-7456.175694] [PMID: 27011750]

[7] Epars JF, Mavropoulos A, Kiliaridis S. Changes in the location of the human mandibular foramen as a function of growth and vertical facial type. Acta Odontol Scand 2015; 73(5): 375-9.

[http://dx.doi.org/10.3109/00016357.2014.968871] [PMID: 25330162]

[8] Al-Shayyab MH. A simple method to locate mandibular foramen with cone-beam computed tomography and its relevance to oral and maxillofacial surgery: a radio-anatomical study. Surg Radiol Anat 2018; 40(6): 625-34

[http://dx.doi.org/10.1007/s00276-018-2015-3] [PMID: 29737379]

[9] Kang SH, Byun IY, Kim JH, Park HK, Kim MK. Three-dimensional anatomic analysis of mandibular foramen with mandibular anatomic landmarks for inferior alveolar nerve block anesthesia. Oral Surg Oral Med Oral Pathol Oral Radiol 2013; 115(6): e17-23.

[http://dx.doi.org/10.1016/j.oooo.2011.10.038] [PMID: 22771406]

[10] Kobayashi K, Shimoda S, Nakagawa Y, Yamamoto A. Accuracy in measurement of distance using limited cone-beam computerized tomography. Int J Oral Maxillofac Implants 2004; 19(2): 228-31. [PMID: 15101594]

[11] Ghabraei S, Shubbar A, Nekoofar MH, Nosrat A. Anesthetic efficacy of mental/incisive nerve block compared to inferior alveolar nerve block using $4 \%$ articaine in mandibular premolars with symptomatic irreversible pulpitis: A randomized clinical trial. Clin Oral Investig
$2019 ; 23(2): 839-45$

[http://dx.doi.org/10.1007/s00784-018-2500-4] [PMID: 29882110]

[12] Predoiu M, Rusu MC, Chiriţă AL. A rare anatomic variation: Triple mental foramina Morphologie. 2019; 103: pp. (341Pt2)110-5.

[13] Iwanaga J, Watanabe K, Saga T, et al. A novel method for observation of the mandibular foramen: Application to a better understanding of dental anatomy. Anat Rec (Hoboken) 2017; 300(10): 1875-80. [http://dx.doi.org/10.1002/ar.23639] [PMID: 28681490]

[14] Jang HY, Han SJ. Measurement of mandibular lingula location using cone-beam computed tomography and internal oblique ridge-guided inferior alveolar nerve block. J Korean Assoc Oral Maxillofac Surg 2019; 45(3): 158-66

[http://dx.doi.org/10.5125/jkaoms.2019.45.3.158] [PMID: 31334104]

[15] Dos Santos Oliveira R, Maria Gomes Oliveira A, Cintra Junqueira JL, Kühl Panzarella F. Association between the anatomy of the mandibular canal and facial types: A cone-beam computed tomography analysis. Int J Dent 2018; 20185481383 [http://dx.doi.org/10.1155/2018/5481383] [PMID: 30275831]

[16] Findik Y, Yildirim D, Baykul T. Three-dimensional anatomic analysis of the lingula and mandibular foramen: a cone beam computed tomography study. J Craniofac Surg 2014; 25(2): 607-10. [http://dx.doi.org/10.1097/SCS.0b013e3182a30ec3] 24448541]

[17] Sekerci AE, Cantekin K, Aydinbelge M. Cone beam computed tomographic analysis of the shape, height, and location of the mandibular lingula in a population of children. BioMed Res Int 2013; 2013: 825453 .

[http://dx.doi.org/10.1155/2013/825453] [PMID: 24490173]

\section{(C) 2019 Correa et al.}

This is an open access article distributed under the terms of the Creative Commons Attribution 4.0 International Public License (CC-BY 4.0), a copy of which is available at: (https://creativecommons.org/licenses/by/4.0/legalcode). This license permits unrestricted use, distribution, and reproduction in any medium, provided the original author and source are credited. 